Video Media

\title{
Acquisitions in a College Library
}

\section{William H. Walters}

This article presents an introduction to the acquisition of video media (DVD and $V H S)$ in academic libraries, with emphasis on the policies and procedures most appropriate for undergraduate colleges. The article discusses several issues-collection development, copyright, identification and evaluation of video titles, acquisitions procedures, budgets and expenditures, and vendor selection and performance-drawing on data and examples from the video media acquisitions program of St. Lawrence University. Although the goal of developing a permanent video collection is not always compatible with the day-to-day operation of an instructional audiovisual service, even small colleges can build collections of lasting value by developing and applying systematic guidelines for the selection and acquisition of video titles.

In July 2000, St. Lawrence University transferred responsibility for the acquisition, cataloging, and processing of audiovisual media from the information technology division to the university libraries. This article explores the acquisition of video media in academic libraries, drawing on the initial experience of the library at St. Lawrence University. It documents the library experiences in acquiring video media and provides an account of collection development, copyright, identification and evaluation of video titles, acquisitions procedures, budgets and expenditures, and vendor selection and performance, with additional information on the cataloging and circulation of video resources. (In this article, "video" refers to video recordings on DVD, VHS tape, and similar media.)

St. Lawrence University, located in Canton, New York, is an undergraduate liberal arts college of approximately 2,000 students. The library collection includes nearly a million books and government documents, 8,000 print and online periodicals, and 4,400 video titles. Three full-time staff, including one librarian, handle print, online, and video acquisitions. This report is not intended as a description of best practices. Instead, it documents the work of a small acquisitions department that gained responsibility for video acquisitions without a corresponding increase in staff or budget.

While both Library Journal and American Libraries have published several essays about video collections and services, both have maintained a relentlessly narrow focus on public and K-12 libraries. Likewise, several authors provide guidance that is valuable for public and school libraries but far less useful in the college/university setting (Hedges 1993; Mason-Robinson 1996; Scholtz 1989). In one of the few articles to examine video operations in an academic library, Hardy and Sessions (1985) describe the consolidation of media services at California State University-Chico (CSU_Chico), where videos had formerly been acquired by three separate agencies: the University Library, the Computer Center, and the Instructional Media Center. Hardy and Sessions do not focus on acquisitions,

however, and the video media program of St. Lawrence University is not directly

edu) is Collection Development Coordinator and Acquisitions Librarian at Owen D. Young Library, St. Lawrence University, Canton, New York.

This article could not have been written without the advice and assistance of Renée Dominie, Denise Dingman, Bart Harloe, Esther Wilder, and two anonymous referees. 
comparable to that of CSU-Chico. One important difference is the setting. St. Lawrence is a small liberal arts college and not a comprehensive university. A second difference can be seen in the position of video media within the broader operations of the library. While CSU-Chico has a separate audiovisual center with eight full-time staff members, St. Lawrence has no staff working solely on video acquisitions and services. The St. Lawrence video acquisitions program emphasizes the mainstreaming of video resources-the idea that the fundamental principles of collection development (the concepts and practices that first evolved in a print-centered environment) can be modified for use with a broad range of media types and formats.

\section{Video Media in Academic Libraries}

Survey evidence suggests that most academic libraries gained control of their institutions' video collections only recently. In 1977, for example, the audiovisual collections of most Association of Research Libraries (ARL) universities were managed by agencies other than the university libraries (Brancolini 2002). Six years later, only 3 of 12 major research libraries maintained video collections of more than 1,000 titles. Seven had more than 20 video titles but fewer than 1,000. The Stanford University libraries reported a single video title, and Harvard reported none (Whichard 1985). The situation had changed substantially by 1993 , however, when $84 \%$ of ARL libraries included video recordings in their collections. Two years later, the proportion had risen to 93\% (Brancolini and Provine 1993, 1997). Even in the mid1990s, however, the acquisition of video media was an activity often shared with other departments on campus. In a 1993 ARL survey, 80\% of responding libraries reported that their universities maintained at least one video collection outside the library - in media centers, information technology agencies, academic departments, and other offices. That same year, the typical ARL library had a permanent collection of only 1,800 VHS tapes, 143 beta cassettes, and 575 films (Brancolini and Provine 1993).

According to Scholtz (1995), the recent growth of academic video collections can be attributed largely to improvements in video technology. Just as VHS tape brought a level of convenience not attainable with $16 \mathrm{~mm}$ film, DVD technology provides a higher level of archival permanence than either film or magnetic tape. The largescale development of video services and collections is therefore linked to the attainment of satisfactory levels of convenience (VHS) and permanence (DVD). The use of video in colleges and universities also can be traced to a second factor: the rise of film studies as a recognized academic discipline. Self (1994) and Dykyj (2002) describe the ways in which theatrical films have been used in college teaching, both in film studies programs and in departments such as English, sociology, and history.

At St. Lawrence University, the transition to a librarybased video collection was accompanied by a realization that the processes and standards used in the acquisition, cataloging, and dissemination of print materials could be applied, with modification, to video resources. As Brancolini and Provine (1997) note, library-based video collections have several advantages. They are more widely available, better cataloged, more readily accessible, and more closely linked to instruction and research than those managed outside the library. The St. Lawrence experience suggests that library control of the acquisitions function brings even greater advantages. These are:

- the application of professional and scholarly standards that align the video collection more closely with the academic mission of the university;

- cost savings (through greater efficiency, volume discounts, better knowledge of alternate vendors, and the elimination of duplicate purchases);

- greater equity among academic departments through the systematic allocation of library funds; and

- the promotion of a long-term outlook focused on collection building rather than the provision of short-term services for particular faculty or courses.

Another advantage, in many instances, is the ability to handle a greater number of acquisitions over a sustained period of time. This is the case at St. Lawrence, where the number of video acquisitions increased significantly when the acquisitions function was transferred to the library. From 1992 to 1999, the library acquired an average of 251 videos per year, and from 2000 to 2002, 356 videos per year, a $42 \%$ increase (see table 1 ).

\section{Collection Development}

In 1985, few academic libraries had collection development policies for video media (Whichard 1985). The situation had improved only slightly by 1993, when $33 \%$ of the ARL member libraries with video collections had separate collection development policies for videotapes or audiovisual materials (Brancolini and Provine 1993). Pitman (1989, 1992) lists several reasons for the failure to develop written policies: the fact that most video collections were established only recently, the rapid pace of economic and technological change, the presence of nonsystematic price disparities that make it difficult to predict the budgetary impact of any particular policy, the small size of most video budgets and staffs, and the absence of reliable selection tools for documentary videos. 
Table 1. St. Lawrence University Video Acquisitions by Year and Format

\begin{tabular}{lccc}
\hline Year & VHS & Laserdisc & DVD \\
1984 & 43 & 0 & 0 \\
1985 & 6 & 0 & 0 \\
1986 & 276 & 0 & 0 \\
1987 & 36 & 0 & 0 \\
1988 & 143 & 0 & 0 \\
1989 & 86 & 0 & 0 \\
1990 & 435 & 0 & 0 \\
1991 & 261 & 0 & 0 \\
1992 & 344 & 0 & 0 \\
1993 & 277 & 0 & 0 \\
1994 & 375 & 45 & 0 \\
1995 & 317 & 14 & 0 \\
1996 & 190 & 8 & 0 \\
1997 & 180 & 2 & 0 \\
1998 & 123 & 0 & 0 \\
1999 & 123 & 0 & 11 \\
2000 & 368 & 0 & 36 \\
2001 & 357 & 0 & 11 \\
2002 & 282 & 0 & \\
Note: $n=4,364$ cataloged titles. & & \\
\hline
\end{tabular}

Despite these difficulties, several authors offer guidance for libraries seeking to establish collection policies for audiovisual media. Together, the outlines prepared by Bosch, et al. (1994), Scholtz (1989, 1991, 1995, 2002), and Brancolini (2002) list several common elements that ought to be included in a comprehensive collection development policy:

1. Introduction and goals: How does the video collection support the institutional mission?

2. Overview of the collection and the community served

3. Scope of the collection (subjects, genres, collecting intensity, geographical regions of interest, languages, physical formats, coding/transmission formats)

4. Selection tools (reviews and other information sources): How are potentially useful titles identified?

5. Evaluation criteria for video titles

6. Selection responsibilities and procedures

7. Copyright compliance and public performance rights

8. Handling of gift materials

9. Withdrawal and replacement

10. Preservation and storage

11. Policies and procedures for reconsideration of challenged materials

12. Collection evaluation techniques and procedures

13. Related collections and cooperative collection development strategies.

Brancolini and Provine (1993) present eleven ARL audiovisual policies that can supplement the elements presented here.
The video policy used at St. Lawrence University is still in draft form and has not yet been approved by constituents outside the library. It addresses seven of the elements mentioned above, but does not yet include items 2, 6, and 10 through 13. Although the process of designing the policy has helped focus attention on several important issues, the document itself has not been used very often. In particular, the faculty have been far more concerned with video budgets and ordering procedures than with collection development policy. Librarians have occasionally referred to the policy when answering specific questions from patrons, however; for example, "Can I add my tape of last night's news to the library collection?" (no), "May I order both DVD and VHS versions of a particular title?" (probably not), and "Can we get this foreign language film that's available only in PAL format?" (probably yes).

While much of the collection policy is specific to St. Lawrence, three general points can be made. First, the library is building a permanent collection. "A library collection, including its video component, is a permanent set of materials owned by the library and intended for long term use. ... While video resources of short term utility may be disseminated through the Information Technology Division, these materials will not be added to the library collection" (St. Lawrence University Libraries 2003).

Second, collection building activities encompass a variety of subjects and genres. This point is made in the following statement:

A wide range of video resources may be suitable for acquisition: commercially released films; dramatizations of literary works; high quality art films; recordings of live theatrical productions; commentary, criticism, and analysis by subject experts in areas outside the expertise of the faculty; documentaries; foreign language practice and drill (if the video component is vital to the presentation); lectures of exceptional quality; news and current events programs; political speeches and debates; and presentations of technical or scientific lab procedures. The assumption underlying the acquisition of popular films and other dramatic works is that they are educationally valuable in several ways: as aids to our understanding of literature and drama, as examples of the performing arts, as guides to rhetorical styles and devices, and as indicators of historical and cultural conditions (St. Lawrence University Libraries 2003).

Third, the library does not seek disciplinary or ideological balance within each title added to the collection. Not all viewpoints can be represented in a typical sixty-minute program, and no assumption of objectivity or balance is implied. 
At the same time, the library does make an explicit attempt to acquire materials that students are unlikely to encounter outside the academic environment.

One specific point is worth mentioning-the library's preference for DVDs instead of VHS tapes. While DVDs comprise only $2 \%$ of the items in the video collection, they are superior to videocassettes in several respects. These are: better sound and picture quality; the ability to move between sections easily (especially in a classroom setting, where the instructor may want to focus on a particular scene); the presence, in most cases, of English and foreign language subtitles; and the ability to show the image in both widescreen and standard television formats. More important, however, is the greater durability and permanence of DVDs. While the physical life of DVD media has not yet been determined, videotapes stored under normal operating conditions are likely to show noticeable signs of deterioration after only fifteen years (Clark 2002; Crawford 1999; Murphy 1997; Wilkie 1999). This is consistent with the library's replacement rate for VHS media. About one severely damaged tape is discovered each month. DVDs are also compatible with digital computer technology; this may allow preservation and use of digitally recorded programs after the physical disc medium becomes obsolete. This preference for DVDs is likely to have a major impact only on feature film purchases, however, since many documentaries are still available solely on VHS.

St. Lawrence's copyright guidelines for video media were developed only recently (see appendix A). They are based on a review of the literature, attendance at several workshops, and consultation with attorneys working in this area. They draw on the ALA Copyright Primer (Bruwelheide 1995) and recent developments in copyright law (ALA 2003; ARL 2003a). While Handman (2002a) provides an up-to-date summary of copyright issues for video media, he devotes insufficient attention to the educational exemptions that allow for the use of videos in face-to-face teaching in nonprofit educational institutions. In particular, Handman overstates the need for public performance rights, which are not required in many instructional settings.

\section{Identification and Evaluation of Video Titles}

Unfortunately, a central goal of print collection development-the selection of resources in anticipation of future need-has not been realized at St. Lawrence University. This can be attributed partly to the cost of videotapes and DVDs. Because the average price of a documentary video is more than $\$ 130$, poor selections can be costly. A more serious problem, however, is the absence of an established infrastructure for the identification and evaluation of video titles.
While the selection of print resources is facilitated by a wide range of sources, tools, and conventions that have developed over time, few reliable guides are available for nonprint media (Walters 1999). Moreover, the video guides that do exist tend to focus on the titles most appropriate for public and school libraries. Albitz (2002), for example, presents a comprehensive list of selection tools for video media. She covers print and online video catalogs, bibliographic utilities, distributors' lists and current awareness publications, online discussion lists, review sources, and major video awards. Nonetheless, her guide includes relatively little information about the documentary titles that are especially valuable to many college libraries. For other lists of selection tools, see Dykyj (2002), Mason-Robinson (1996), Pitman (1992), Scholtz (1989, 2002), and Self (1994).

At St. Lawrence, the guides by Goldman and Sanders (2002) and Handman (2002b, 2002c) have been especially helpful in the identification and evaluation of documentary videos. At the same time, the absence of objective selection tools for documentaries has led to a heavy reliance on publishers' catalogs and Web sites. The disadvantages of this situation are obvious. Commenting on a 1987 survey that revealed that vendors' catalogs were the primary video selection tools used in public libraries, Pitman noted, "This is, of course, an appalling finding. It would be like handing a book selection head a Publisher's Central Bureau catalog with instructions to build a balanced collection" $(1989,102)$. While distributors' announcements and catalogs are the main selection tools used at St. Lawrence, the librarians do rely on a wide range of information sources: Web sites, published reviews, discussion lists, trade journals, and colleagues at other libraries.

Because St. Lawrence has no full-time subject bibliographers, primary responsibility for video selection rests with the faculty. Specifically, departmental faculty select $77 \%$ of the videos acquired; $8 \%$ are selected by the collection development librarian, and $15 \%$ by other librarians and staff. These percentages are comparable to those reported by ARL libraries, in which faculty select $68 \%$ of all video titles (Brancolini and Provine 1993). St. Lawrence faculty are expected to be aware of what is available, to evaluate particular titles of interest, and to request that those titles be purchased by the library staff. In turn, the acquisitions staff have four primary selection responsibilities: to obtain and disseminate selection tools (chiefly catalogs and announcements); to recommend particular titles, both spontaneously and in response to patrons' requests; to ensure, through fund management, that the acquisition of high cost videos does not compromise the library's ability to purchase other materials; and to provide additional guidance and assistance as necessary. The second responsibility-recommendation of titles-has increased in significance over time and is now the primary means by which the acquisitions staff influence 
video collection development. Library activities in this area are twofold:

- The library solicits and welcomes the faculty's assessments of particular titles. These assessments, along with other information, are used to identify the distributors most likely to offer high quality, cost-effective documentaries. Once identified, the relevant catalogs and Web sites are examined regularly for important new releases.

- Many of the video orders submitted by faculty are reviewed in an effort to identify less expensive or more appropriate titles. Admittedly, this practice began as an attempt to save money, not an attempt to improve the collection. However, the process of evaluating these orders (looking for reviews, related resources, and alternate vendors) has led to greater familiarity with the needs of particular departments and an improved ability to recommend good titles for purchase.

The evaluation of videotapes and DVDs is done mainly by the departmental faculty, although the acquisitions staff do monitor all video orders for potential problems related to format, cost, licensing, or copyright. Librarians also recommend titles already available within the collection, and these efforts have been well received. The evaluation criteria used by the faculty and acquisitions staff can be seen in Appendix $\mathrm{B}$. These guidelines are consistent with those recommended in the literature (Blenz-Clucas 2002; Brancolini 2002; Scholtz 1989, 1991, 2002; Self 1994).

\section{Acquisitions and Expenditures}

In most cases, the acquisitions process begins when an order is received from a member of the university's faculty or staff. Over eighteen months (July 1, 2001 through December 31, 2002), 482 orders were placed by 82 individuals. While the majority of selectors placed 3 orders or fewer, 19 individuals placed more than 10 orders each. The acquisitions staff are happy to consider video requests from students, but only one or two requests from students were received during that eighteen-month period.

Excluding titles ordered by librarians and other staff, $42 \%$ of recent video orders were placed by faculty in the humanities; $28 \%$ were placed by faculty in the social sciences, $5 \%$ by faculty in the natural sciences, and $25 \%$ by faculty representing interdisciplinary programs. The individual departments placing the most video orders were sociology (55 orders), global studies (51 orders), gender studies (44 orders), music (31 orders), and English (30 orders). Several departments placed no orders at all, and the typical (median) department ordered just 9 videos.
As might be expected, newer faculty are more likely to use videos in their courses. Of the 182 tenured and tenure track faculty at St. Lawrence, 35\% placed one or more video orders from July 2001 through December 2002. While 44\% of assistant professors ordered one or more videos, only $32 \%$ of associate professors and $27 \%$ of professors did so. This suggests that assistant professors are more comfortable with video technology and more likely to regard video as a legitimate medium of instruction. Two local factors also may help account for this trend. They are:

- Special book/video funds are available for the use of first-year faculty.

- Newer faculty tend to be more familiar with the library's video acquisitions program, which began just as many of them were arriving at the university.

For many new faculty, the video acquisitions program is their first point of contact with the library. The process of building a video collection (exchanging information about courses, research interests, new titles, copyright, and so on) helps to maintain the relationships that are vital to library work in a small college setting.

As table 2 shows, the St. Lawrence video collection includes equal numbers of documentaries and feature films. The library's video expenditures are not evenly divided, however, since documentaries are far more expensive than other titles. While English-language theatrical releases can usually be obtained for less than $\$ 15$, most documentary videos cost $\$ 130$ or more. The primary cause of this price disparity is the small market for documentary films - specifically, the fact that start-up and production costs must be split between a relatively small number of potential purchasers (Scholtz 1995; Franco 2002). At least one author has predicted that the prices of special interest videos will decline over time as the market matures and distributors sell more copies directly to consumers (Scholtz 1991). This trend does seem to be occurring within particular niche markets (the History Channel, the Discovery Channel, etc.) but not as a general pattern.

At St. Lawrence University, library funding of video purchases was fully implemented in July 2000 , with the establishment of a new, nondepartmental video account of $\$ 15,000$ for the $2000-01$ fiscal year. The intent was to accommodate all reasonable video requests, charging them to the new account and letting the demand for video media establish the level of funding to be used in subsequent years. That year, video expenditures were much higher than expectednearly $\$ 27,000$. In an effort to control costs in 2001-02, the separate video fund was eliminated and most videos were charged to the departmental book accounts. The departmental accounts received modest increases, and a separate fund was established to support book and video purchases 
Table 2. Cost of Recently Acquired Videos by Genre

\begin{tabular}{lccc}
\hline Genre & $\begin{array}{c}\text { \% in } \\
\text { genre }\end{array}$ & $\begin{array}{c}\text { Average } \\
\text { price (\$) }\end{array}$ & $\begin{array}{c}\text { Median } \\
\text { price (\$) }\end{array}$ \\
$\begin{array}{l}\text { Feature film or recorded } \\
\quad \text { performance-English language }\end{array}$ & 33 & 24 & 15 \\
$\quad \begin{array}{l}\text { Feature film or recorded } \\
\quad \text { performance-other language }\end{array}$ & 14 & 57 & 35 \\
$\quad \begin{array}{l}\text { Documentary-society and culture } \\
\text { Documentary-science }\end{array}$ & 46 & 135 & 125 \\
$\quad$ Instructional (focusing on a & 3 & 123 & 78 \\
$\quad$ particular task, skill, or procedure) & 4 & 124 & 134 \\
All genres combined & $\mathbf{1 0 0}$ & $\mathbf{8 7}$ & $\mathbf{3 6}$ \\
Note: $n=421$ titles ordered and received from July 1, 2001 through \\
$\quad$ December 31, 2002.
\end{tabular}

on behalf of first-year faculty and newly offered courses. (The first-year fund was not part of the library's video acquisitions program, but an independent development.) As might be expected, video expenditures declined in 2001-02, from $\$ 27,000$ to $\$ 22,000$. St. Lawrence followed the same budget strategy again in 2002-03, with somewhat higher expenditures $(\$ 14,500)$ during the first six months of the year. Clearly, some departments have been willing to reduce their book expenditures in order to purchase more video titles. More than a third of recent video orders have been funded from a special "new faculty" fund, however. This budget line has no direct impact on the departmental book and video accounts.

In comparison with the major research universities, St. Lawrence spends a relatively large amount on videos. Over the past three years, video expenditures have accounted for 2.0 to $2.5 \%$ of the total acquisitions budget. In contrast, most large research libraries with video collections report audiovisual expenditures in the range of $0.8 \%$ (Brancolini and Provine 1993). While a $1 \%$ minimum guideline has been advocated for major research libraries (Brancolini 2002), this percentage is likely to be exceeded at many liberal arts colleges. Because videos are used primarily for instruction rather than research, one might reasonably expect that institutions with a teaching focus will spend relatively more money on video acquisitions.

\section{Vendor Selection and Performance}

Vendor selection is perhaps the most challenging component of video acquisitions. For feature films, the difficulty lies in finding a single vendor able to handle most orders without substantial intervention from the library staff. The ideal is a vendor able to process video orders in much the same way as book orders. For documentaries, the difficult task is identifying the distributor best able to supply each individual title.
Pitman (1992), Scholtz (1989, 1995), and Mason-Robinson (1996) provide helpful lists of video vendors.

At St. Lawrence, nearly all orders for English-language feature films are placed with Baker and Taylor or Amazon.com. Baker and Taylor is the first choice vendor, mainly for reasons of cost. They provide a $25 \%$ price discount on all video titles. For Baker and Taylor, the median time from order to receipt is twenty-one days, and $67 \%$ of all orders arrive within thirty days. At the same time, the library uses Amazon.com for feature films not listed in Baker and Taylor's online catalog. The performance data for Amazon.com are virtually identical to those for Baker and Taylor, although the median cost of an Amazon.com video is higher $-\$ 20$ rather than $\$ 11$. For Baker and Taylor orders, the library generates printed purchase orders through the library's INNOPAC system. Orders are placed online with Amazon.com, and the bibliographic and order records are created separately in INNOPAC. Both vendors require the establishment of institutional accounts before any orders are placed.

The St. Lawrence faculty provide vendor information for approximately half the documentaries they request. For other documentary videos, the process of verifying bibliographic information and identifying a distributor is likely to include some or all of the following components:

- Checking if the video is available through Baker and Taylor or Amazon.com

- Searching OCLC WorldCat for bibliographic information

- Searching the online catalogs of the specialized video distributors that seem most appropriate (PBS, Women Make Movies, etc.)

- Searching the printed catalogs of video vendors (these are received and kept in the acquisitions office)

- Using online search engines to find information that may lead to the identification of a vendor (production information, screening dates and locations, reviews, other libraries' holdings, etc.).

Table 3, constructed using the same methods conventionally employed in the evaluation of print vendors (Bracken and Calhoun 1984; Miller and Niemeier 1987; Vendor Study Group 1992), provides basic information about the performance of the video suppliers used most often at St. Lawrence University. These suppliers can be classified into three groups: feature film vendors (Baker and Taylor, Amazon.com), specialty distributors (those that supply only the items listed in their catalogs, usually on behalf of independent documentary producers), and general vendors (those that supply feature films, documentaries, and other videos from a broad range of sources). As the table shows, the top 15 vendors vary markedly in their fulfillment rates, response 
Table 3. Vendor Statistics: Fulfillment Rates, Response Times, and Prices

\begin{tabular}{|c|c|c|c|c|c|c|c|c|}
\hline & $\begin{array}{l}\% \text { orders } \\
\text { placed with } \\
\text { vendor }\end{array}$ & $\begin{array}{l}\% \text { rcvd. } \\
\text { within } \\
10 \text { days }\end{array}$ & $\begin{array}{l}\% \text { rcvd. } \\
\text { within } \\
30 \text { days }\end{array}$ & $\begin{array}{l}\% \text { cancelled } \\
\text { (unfilled) }\end{array}$ & $\begin{array}{l}\text { Average time } \\
\text { order to } \\
\text { receipt }\end{array}$ & $\begin{array}{l}\text { Median time } \\
\text { order to } \\
\text { receipt }\end{array}$ & $\begin{array}{l}\text { Average } \\
\text { price (\$) }\end{array}$ & $\begin{array}{c}\text { Median } \\
\text { price (\$) }\end{array}$ \\
\hline \multicolumn{9}{|l|}{ Feature film vendors } \\
\hline Baker \& Taylor & 22 & 3 & 67 & 18 & 24 & 21 & 17 & 11 \\
\hline \multicolumn{9}{|l|}{ General vendors } \\
\hline Ambassador Media & 1 & 0 & 14 & 71 & 59 & 59 & 121 & 121 \\
\hline Annenberg/CPB & 1 & 0 & 100 & 0 & 20 & 20 & 94 & 40 \\
\hline Chiapas Media Project & 2 & 0 & 0 & 0 & 60 & 60 & 67 & 70 \\
\hline Ctr. for South Asia, U. WI & 1 & 0 & 33 & 0 & 52 & 63 & 131 & 131 \\
\hline Facets Multi-Media & 11 & 2 & 65 & 8 & 34 & 21 & 34 & 20 \\
\hline Filmakers Library & 1 & 50 & 100 & 0 & 16 & 14 & 363 & 350 \\
\hline \multicolumn{9}{|l|}{ Films for Humanities \& } \\
\hline PBS Video & 4 & 0 & 78 & 6 & 28 & 23 & 47 & 30 \\
\hline Women Make Movies & 1 & 0 & 100 & 0 & 16 & 13 & 237 & 225 \\
\hline \multicolumn{9}{|l|}{52 other distributors } \\
\hline (combined) & 15 & 18 & 75 & 5 & 27 & 17 & 121 & 100 \\
\hline All vendors combined & 100 & 6 & 68 & 10 & 28 & 21 & 87 & 37 \\
\hline
\end{tabular}

times, and prices. The price differentials can be attributed at least partly to the fact that some distributors will not sell videos without the accompanying public performance rights. These rights are not required in most educational contexts. Nonetheless, public performance rights are included in the cost of all videos distributed by Annenberg/CPB, Films for the Humanities and Sciences, First Run Icarus Films, and the Media Education Foundation.

St. Lawrence has made special attempts to find reliable suppliers in the general vendors category-vendors able to supply out-of-print videos as well as those for which a specialty distributor cannot be identified. Only Siena Library Company of York, Pennsylvania, has met the library's requirements in this regard. Siena handles a wide variety of the library's video orders, especially those that have been returned unfilled by other vendors. They are able to supply more than $80 \%$ of the orders the library places, with a median response time no higher than that of the specialty distributors. Siena's performance is clearly superior to that of Ambassador Media, the library's other supplier in this category. However, both Siena and Ambassador have been more effective than Professional Media Service Corporation (PMSC). PMSC claims to offer the largest selection of any video vendor, to supply "even the hardest to find titles" and "those that previously have only been available directly from the producer" (Professional Media Service Corporation
1999). The library's experience has not been consistent with these claims. The 20 orders sent to PMSC, most in August 2000 , resulted in only one video, 141 days later. A second order was cancelled after 41 days because it would not have arrived in time for its intended use. The remaining 18 purchase orders were returned by PMSC, 4 with the notation "unable to supply," 4 marked "out of print," 4 marked "order direct," and 3 had the message "unknown vendor." The remaining 3 were labeled "unknown title," "vendor doesn't carry title," and "no vendor found." This performance may not be typical of PMSC, but it did dissuade the library from placing further orders with them.

A substantial number of video orders were placed with a second vendor after the first vendor could not fill the order. Consequently, the 482 orders shown in table 3 represent just 460 unique titles. The cancelled column shows the percentage of orders that could not be filled by each vendor. Only a few orders were cancelled for other reasons. Overall, $89 \%$ of the video titles ordered by the library were supplied by the first vendor with whom the order was placed. For those titles, the median time from order to receipt was 21 days, with $77 \%$ arriving within 30 days. Three percent of titles could not be supplied by the first attempt vendor, but were subsequently furnished by the second or third attempt vendors. Those titles took significantly longer to acquire, and only $15 \%$ arrived within 30 days of the initial order. Six percent of the video 
Table 4. Circulation of Recently Acquired Videos by Genre

\begin{tabular}{|c|c|c|c|c|}
\hline Genre & $\begin{array}{l}\% \text { in } \\
\text { genre }\end{array}$ & $\begin{array}{c}\% \text { circulating } \\
\text { at least } \\
\text { once }\end{array}$ & $\begin{array}{c}\% \text { circulating } \\
3 \text { or more } \\
\text { times }\end{array}$ & $\begin{array}{l}\text { Average } \\
\text { circulation }\end{array}$ \\
\hline Feature film or recorded performance—English language & 32 & 58 & 16 & 1.1 \\
\hline Documentary_-society and culture & 45 & 55 & 20 & 1.5 \\
\hline Documentary—science & 3 & 83 & 23 & 1.7 \\
\hline Instructional (focusing on a particular task, skill, or procedure) & 6 & 47 & 23 & 1.1 \\
\hline
\end{tabular}

titles ordered by the library were permanently cancelled after one or more unsuccessful attempts, and $2 \%$ were still on order (and expected to arrive) as of December 31, 2002.

\section{Cataloging and Circulation}

Nearly all the videos acquired by St. Lawrence University are cataloged in ODYsseus, the library's public access INNOPAC catalog. Videotapes and DVDs are therefore searchable within the main catalog by title, author, title plus author, words in title, subject heading, and call number. Moreover, a link on the ODYsseus home page leads to a separate video search interface that retrieves only video records. (In that interface, the author search is labeled "Director, Actor or Producer.") All video records include subject headings, although the call numbers assigned to videos are not classification numbers. Each call number consists of a format code (IMV, IMD, or IML), the year of acquisition, and an accession number within that year. The median time from receipt to cataloging is just 7 days. Forty-three percent of videos are cataloged within 5 days of receipt, and just $8 \%$ (chiefly foreign language titles) take longer than 30 days to catalog. The library's cataloging practices are consistent with those used in major research libraries. According to Brancolini and Provine, 93\% of ARL libraries with video collections catalog their videos, either fully or partially. Only $42 \%$ use classification numbers as video call numbers, however (Brancolini and Provine 1993, 1997). For comprehensive discussions of video cataloging, see Scholtz (1995) and Wilkie (1999).

At St. Lawrence, the Information Technology Divisionan agency separate from the library - is currently responsible for video storage and dissemination. All faculty, staff, and students may borrow videos, although the loan period varies: 7 days for St. Lawrence faculty, 5 days for staff, and 3 days for all other patrons (including faculty at nearby colleges). The circulation rate for newly acquired videos is high, with an average of 1.4 circulations for each item cataloged within an eighteen-month period (July 1, 2001 through December 31,
2002). Moreover, even those videos that have been in the collection for a number of years continue to circulate regularly. Approximately $23 \%$ of the videos in the collection were borrowed at least once during the 2001-02 fiscal year.

Somewhat surprisingly, English-language feature films are borrowed less often than documentaries (see table 4). This may reflect the instructional strategies used by the faculty. When a particular documentary is assigned to a class, all students are expected to watch it, either in class or outside class. When feature films are used, individual students or groups sometimes get to choose among several different titles. Although the video collection includes recent releases that have done well commercially, students seem reluctant to borrow videos for recreational use. This may be due to the physical location of the video collection, which is in closed stack storage within the information technology office.

\section{Continuing Challenges for Academic Libraries in Video Media Acquisitions}

Some of the video-related problems faced by St. Lawrence University are local in nature. The video collection is outgrowing its current location, and the on-site viewing facilities and equipment are less than optimal. These concerns will be addressed over the next few years as the university libraries assume responsibility for video circulation and storage.

Other difficulties faced at St. Lawrence are more universal in nature. Library staff need to make it clear to the university community that they are building a collection rather than simply providing a service. While many faculty and staff understand this distinction and its implications, others do not. For instance, one St. Lawrence administrator recently suggested that the library withdraw those videos that had not been borrowed within the past year or two, citing the $23 \%$ annual circulation rate as evidence that many titles could be safely removed. Likewise, the information technology staff were initially resistant to the large-scale acquisition of DVDs due to the university's heavy investment in VHS technology. 
These difficulties show that the goal of building a permanent collection-acquiring the physical medium most likely to offer long-term stability - is not always consistent with the goal of meeting current needs.

Another problem - the absence of proactive collection development -is closely tied to the inadequacy of the video selection tools currently available. For one thing, few sources of reliable information can be found regarding the thousands of documentary videos released each year. Without this information, even selectors with a good knowledge of the college's faculty and curriculum will not feel confident selecting video titles in anticipation of future need. A comprehensive source of bibliographic and vendor information would be especially helpful. Several guides claim to provide this kind of information (Gale 2002; Information Today 2002), but none are complete enough to replace vendors' catalogs or OCLC WorldCat as a source of bibliographic data.

Finally, library patrons tend to have an incomplete awareness of copyright issues, and many feel that a personal standard of reasonableness should take precedence over the guidelines developed by the legal and library professions. As a result, faculty continue to send the library videotapes that have been created in violation of copyright, along with requests to tape televised programs for long-term storage and use. While these difficulties are minor, the absence of a universitywide copyright policy is a larger problem that the university and the library plan to address. In the meantime, the library has developed the guidelines presented in appendix A.

\section{Conclusion}

The goal at St. Lawrence University is to evaluate, select, and acquire video media using rational criteria and standards similar to those that have been developed for print resources. The library has faced several challenges in absorbing responsibility for the acquisition, cataloging, and processing of audiovisual media. Some problems, such as the need for sufficient space and better viewing facilities, can be addressed with adequate funds. Other university issues will take longer to resolve. These include educating administrators and faculty about the purpose and potential of an excellent library collection, improving the quality of selection tools for video media, and promoting a better understanding of copyright issues within the user community.

\section{Works Cited}

Albitz, Rebecca. 2002. Video reference tools and selection aids. In Video collection development in multi-type libraries, $2 \mathrm{~d}$ ed., ed. Gary P. Handman, 343-55. Westport, Conn.: Greenwood.

American Library Association. 2003. Copyright issues. Accessed Apr. 14, 2003, www.ala.org/Content/NavigationMenu/Our_
Association/Offices/ALA_Washington/Issues2/Copyright1/ Copyright.htm.

Association of Research Libraries. 2003a. Copyright and intellectual property. Accessed Apr. 14, 2003, www.arl.org/info/frn/ copy/copytoc.html.

-2003b. Technology, Education, and Copyright

Harmonization (TEACH) Act. Accessed Apr. 14, 2003, www. arl.org/info/frn/copy/TEACH.html.

Blenz-Clucas, Beth. 2002. Some guidelines for evaluating nontheatrical videos. In Video collection development in multitype libraries, 2d ed., ed. Gary P. Handman, 277-85. Westport, Conn.: Greenwood.

Bosch, Stephen, Patricia Promis, and Chris Sugnet. 1994. Guide to selecting and acquiring CD-ROMs, software, and other electronic publications. Chicago: ALA.

Bracken, James K., and John C. Calhoun. 1984. Profiling vendor performance. Library Resources \& Technical Services 28, no. 2 (Apr./June): 120-28.

Brancolini, Kristine R. 2002. Video collections in academic libraries. In Video collection development in multi-type libraries, 2d ed., ed. Gary P. Handman, 47-75. Westport, Conn.: Greenwood.

Brancolini, Kristine R., and Rick E. Provine. 1993. Video collections and multimedia in ARL libraries. SPEC Kit no. 199. Washington, D.C.: Association of Research Libraries. . 1997. Video collections and multimedia in ARL libraries. OMS Occasional Paper no. 19. Washington, D.C.: ARL.

Bruwelheide, Janis H. 1995. The copyright primer for librarians and educators. $2 \mathrm{~d}$ ed. Chicago: ALA.

Clark, Jeff. 2002. Preserving the image: Video preservation. In Video collection development in multi-type libraries, $2 \mathrm{~d}$ ed., ed. Gary P. Handman, 224-41. Westport, Conn.: Greenwood.

Crawford, Walt. 1999. Up to speed on DVD. American Libraries 30, no. 8 (Sept.): 71-74.

Dykyj, Oksana. 2002. Cinema collections: Academic libraries. In Video collection development in multi-type libraries, $2 \mathrm{~d}$ ed., ed. Gary P. Handman, 199-223. Westport, Conn.: Greenwood.

Franco, Debra. 2002. A primer on the home video market. In Video collection development in multi-type libraries, $2 \mathrm{~d}$ ed., ed. Gary P. Handman, 309-22. Westport, Conn.: Greenwood.

Gale Group. 2002. Video source book. 29th ed. Farmington Hills, Mich.: Gale Group.

Goldman, Nancy, and Jason Sanders. 2002. Sources for finding alternative media. In Video collection development in multitype libraries, 2d ed., ed. Gary P. Handman, 378-95. Westport, Conn.: Greenwood.

Handman, Gary P. 2002a. The rights stuff: Video copyright and collection development. In Video collection development in multi-type libraries, 2d ed., ed. Gary P. Handman, 287-305. Westport, Conn.: Greenwood. - 2002b. Screening differences: Resources for building culturally diverse video collections. In Video collection development in multi-type libraries, $2 \mathrm{~d}$ ed., ed. Gary P. Handman, 356-77. Westport, Conn.: Greenwood. - 2002c. Video and film associations, organizations, and discussion lists. In Video collection development in multi- 
type libraries, 2d ed., ed. Gary P. Handman, 406-16. Westport, Conn.: Greenwood.

Hardy, Carol L., and Judith A. Sessions. 1985. Integrated media operations in an academic library: A profile. Library Trends 34, no. 1 (summer): 79-93.

Hedges, Michael. 1993. Managing an integrated video collection. Wilson Library Bulletin 67, no. 10 (June): 32-35.

Information Today. 2002. A.V. market place 2002. Medford, N.J.: Information Today.

Mason-Robinson, Sally. 1996. Developing and managing video collections. New York: Neal-Schuman.

Miller, Ruth H., and Martha W. Niemeier. 1987. Vendor performance: A study of two libraries. Library Resources \& Technical Services 31, no. 1 (January/March): 60-68.

Murphy, William T. 1997. Television and video preservation 1997: A report on the current state of American television and video preservation. Washington, D.C.: Library of Congress.

Pitman, Randy. 1989. A.V. frontier. Wilson Library Bulletin 64, no. 2 (Oct.): 102-03.

1992. The video librarian's guide to collection development and management. New York: G. K. Hall.

Professional Media Service Corporation. 1999. Professional Media Service Corporation: The one-stop solution for shelfready audio-visual materials. Accessed Apr. 14, 2003, www. promedia.com/main.htm.
Scholtz, James C. 1989. Developing and maintaining video collections in libraries. Santa Barbara, Calif.: ABC-CLIO.

. 1991. Video policies and procedures for libraries. Santa Barbara, Calif.: ABC-CLIO.

. 1995. Video acquisitions and cataloging. Westport, Conn.: Greenwood.

2002. Developing video collection development policies to accommodate existing and new technologies. In Video collection development in multi-type libraries, $2 \mathrm{~d}$ ed., ed. Gary P. Handman, 245-76. Westport, Conn.: Greenwood.

Self, James. 1994. Cinema on video in academic libraries. In Video collection development in multi-type libraries, ed. Gary P. Handman, 207-24. Westport, Conn.: Greenwood.

St. Lawrence University Libraries. 2003. Collection development policy for videotapes and videodiscs. Unpublished document. Available on request.

Vendor Study Group. 1992. Regional study of vendor performance for in-print monographs. Library Acquisitions: Practice and Theory 16, no. 1: 21-29.

Walters, William H. 1999. Building and maintaining a numeric data collection. Journal of Documentation 55, no. 3 (June): 271-87.

Whichard, Mitchell. 1985. Collection development and nonprint materials in academic libraries. Library Trends 34, no. 1 (summer): 37-53.

Wilkie, Chris. 1999. Managing film and video collections. London: Aslib.

\section{Appendix A Copyright Guidelines in Use at St. Lawrence University}

1. Videotapes and DVDs may be freely loaned or rented to individuals (staff, students, and members of the general public) for private viewing. This applies regardless of the intended use, educational or otherwise.

2. Instructors and students in nonprofit educational institutions may show videotapes or DVDs in class as part of the required instructional activities. There is no limit on the length or amount of a program that may be shown in this context. Distance learning activities are not included under this provision, however (ARL 2003b).

3. It is not entirely clear whether the transmission of videos over an on-campus network is permitted under the fair use and educational exemption provisions of copyright law. If an institution feels that on-campus transmission is permitted, two requirements must be met: the viewing must be a required component of a regular academic course, and the program must be accessible only to those students enrolled in the course.

4. A damaged or deteriorating video may be copied for preservation purposes only if a replacement copy cannot be purchased at a fair price. Copyright law makes no provision for the creation of backup (archival) copies, however, or for transfers from one coding format to another (PAL to NTSC, etc.).

5. Most programs broadcast on television or cable may be taped during transmission and kept for no longer than 45 days. They must be erased or destroyed at the end of that period. Moreover, the tapes may be used for instructional purposes-in-class showings, etc.—only within the first 10 school days after taping.

6. Academic institutions may choose to purchase additional permissions and rights beyond those mentioned here-public performance rights and digital transmission rights, for example. These rights are not required for face-to-face classroom showings in nonprofit educational institutions, however. Note: In 1993, 15\% of ARL libraries with video collections purchased only those videos for which they had acquired the public performance rights (Brancolini and Provine 1993).

7. Academic institutions may choose to accept limitations of their fair-use and educational rights. For example, they may agree to contractual restrictions on use in order to gain access to resources that would otherwise 
be unavailable. Unilateral statements from publishers are not always enforceable, however. For instance, the presence of a "home use only" label does not necessar- ily mean that the video cannot be used for classroom instruction. It means only that the distributor would like users to believe that's the case.

\section{Appendix B Evaluation Guidelines in Use at St. Lawrence University}

We suggest that selectors consider the following criteria when evaluating video titles. Not all criteria will be relevant in all cases, however.

\section{For All Video Resources}

1. Relevance to a particular course or a particular faculty member

2. Relevance to the curriculum more generally

3. Multidisciplinary appeal

4. Availability of similar resources within the collection

5. Expected frequency of use

6. Expected number of users

7. Expected useful life (In particular, will it remain useful after changes in course offerings or content?)

8. Level of presentation (Is it appropriate for an undergraduate audience?)

9. Value in documenting social or historical conditions

10. Potential effectiveness in stimulating discussion or further study

11. Inclusion of social, political, or economic themes or viewpoints not presented elsewhere

12. Regional interest (Does it focus on the "North Country"?)

13. Availability, content, and authority of published reviews

14. Awards and honors received

15. Reputation of creator (playwright, director, composer, etc.)

16. Reputation of distributor (Have we been satisfied with videos previously purchased from this source?)

17. Technical quality of production
18. Appropriateness of video presentation (Do other media offer a more effective means of presenting the content?)

19. Appropriateness of format (Are the physical format and the coding/transmission format supported at St. Lawrence?)

20. Extent to which it supports, or is supported by, library materials in other media (print, online, etc.)

21. Absolute cost (Can we afford it?)

22. Relative cost (Is it worth the price?)

23. Availability of special funding to support the purchase

24. Need for (and availability of) public performance and digital transmission rights.

\section{For Dramatic or Artistic Presentations}

1. Aesthetic appeal

2. Authenticity (absence of post-release editing, availability in widescreen format, etc.)

3. Uniqueness (Is the work representative of a genre or style of which we can acquire just a few specimens? Is the performance different in meaningful ways from other performances of the same work?).

\section{For Documentaries and Other Factual Presentations}

1. Accuracy

2. Authoritativeness

3. Currency (timeliness)

4. Effectiveness of presentation

5. Objectivity (for materials where objectivity is desired or assumed). 